\title{
Enzymatic variability in Aedes aegypti (Diptera: Culicidae) populations from Manaus-AM, Brazil
}

\author{
Elmary da Costa Fraga ${ }^{1}$, Joselita Maria Mendes dos Santos ${ }^{2}$ and Juracy de Freitas Maia ${ }^{2}$ \\ ${ }^{1}$ Universidade Estadual do Maranhão, UEMA/CESC, Caxias, MA, Brazil. \\ ${ }^{2}$ Instituto Nacional de Pesquisas da Amazônia, CPCS, Manaus, AM, Brazil.
}

\begin{abstract}
Eighteen enzymatic loci were analysed in Aedes aegypti populations from four neighbourhoods in the city of Manaus. The analyses showed that the Downtown population was the most polymorphic $(p=55.6 \%)$ with higher observed and expected mean heterozygosities $\left(H_{o}=0.152 \pm 0.052 ; H_{e}=0.174 \pm 0.052\right.$, respectively). The least variability was detected in the Coroado and Cidade Nova populations, both with polymorphism of $44.4 \%$. The latter population presented the least observed heterozygosity $\left(H_{\circ}=0.109 \pm 0.037\right)$. Wright's $F$ statistics showed that the mean value of $F_{\text {is }}$ was higher than that of $F_{s t}\left(F_{i s}=0.164>F_{s t}=0.048\right)$, and from analysis of molecular variance (AMOVA) it was found that $95.12 \%$ of the variability is found within populations indicating a certain intra-population differentiation possibly of the microgeographic structure resulting from some barrier in the random coupling. Although the four populations were similar genetically ( $D=0.003$ to 0.016 ), the $4.88 \%$ differentiation was significant.
\end{abstract}

Key words: Aedes aegypti, electrophoreses, isozymes, populations genetics.

Received: July 8, 2002; accepted: February 4, 2003.

\section{Introduction}

Aedes (Stegomyia) aegypti is a widely geographically distributed species as well as of great epidemiological importance on account of being the major vector involved in the transmission of the yellow fever virus and four serotypes of dengue and its hemorrhagic fever viruses throughout most of the world's tropical and subtropical areas (Chow et al., 1998).

The reintroduction of this vector insect to Brazil in 1967 , which is presently infesting up to 3,592 municipalities nationwide (Honório and Lourenço-de-Oliveira, 2001), has consolidated dengue infection as a major public health problem. Nearly 1.8 million cases have been reported in the past few years. These cases account for about $80 \%$ of the Americas total (Schatzmayr, 2000). High population sizes of this mosquito have been recorded in the city of Manaus, highlighting the magnitude of this problem within the region.

Several studies have addressed the population genetics of this species (Tabachnick, 1982; Wallis et al., 1984; Harrington et al., 1984; Dinardo-Miranda and Contel, 1996; Failloux et al., 1995; de Sousa et al., 2000, 2001; Ravel et al., 2002). These studies dealt with the population genetical structure as an essential requirement to the understanding of population dynamics as well as factors that may

Send correspondence to J.M.M.S. E-mail: jsantos @inpa.gov.br. interact with them, such as vectorial ability, insecticide resistance and ecological adaptation.

In the present study, four populations of $A$. aegypti were analysed using enzymatic variation of 18 loci to characterize the genetic structure of this species in the sampled regions.

\section{Material and Methods}

The mosquitoes were collected in Compensa, Cidade Nova, Coroado and Downtown, neighbourhoods of the city of Manaus. Larvae and pupae collected in artificial breeding sites outdoors were kept in an insectarium until the emergence of the adults. The adults were then transferred to a cage, where the males were fed on a $10 \%$ sucrose solution and the females were fed in a hamster (Mesocricetus auratus). After the couplings, females were isolated for individual oviposition and later identified by means of the Consoli and Lourenço-de-Oliveira (1994) key. Hatched larvae were kept until the electrophoretic analyses specific stages, according to Santos et al. (1981), and frozen in at $-70^{\circ} \mathrm{C}$.

Eighteen enzymatic loci were analysed (EST3, EST4, EST5, EST6, LAP1, LAP2, LAP4, LAP5, LAP6, PGI, HEX1, HEX2, MDH, IDH, ME, 6-PGD, PGM and $\alpha$ $-G P D H$ ). Fourth instar larvae were used for most of the enzymes with the exception of $\alpha-G P D H$, for which adults 
were used. Three individuals from each progeny were used. Electrophoretic techniques and enzyme recipes were those described in Steiner and Joslyn (1979). The gels were prepared as described by Santos et al. (1996).

Allelic frequencies were estimated directly from the data. Polymorphic loci ratio $(\mathrm{P})$, found $\left(\mathrm{H}_{\mathrm{o}}\right)$ and expected $\left(\mathrm{H}_{\mathrm{e}}\right)$ heterozygosities and Wright's coefficients were estimated in each population by using BIOSYS (Swofford and Selander, 1981) program. The dendrogram was constructed employing the UPGMA method (Nei, 1978). Values of $\mathrm{F}_{\text {st }}$ (Weir and Cockerham, 1984), and hierarchical analysis of molecular variance (AMOVA) (Michalakis and Excoffier, 1996) were calculated using the ARLEQUIN program, version 2000 (Schneider et al. 2000), in which significance levels for the overall values were determined after 1023 permutations.

\section{Results}

Only 7 out of the 18 loci analysed presented polymorphism in the four populations: EST4, EST5, LAP2, LAP5, $I D H, M D H$ and $P G M$. The EST3 and LAP6 loci were polymorphic in the Compensa and Downtown populations. The EST3 locus was also polymorphic in the Coroado population. The $P G I$ locus was polymorphic in the Cidade Nova and Downtown populations. The Compensa and Coroado populations were monomorphic (Table 1). Chi-square values for most Compensa population polymorphic loci were

Table 1 - Allele frequency at each polymorphic locus and chi-square value for the determination of Hardy-Weinberg equilibrium in Aedes aegypti populations from Manaus.

\begin{tabular}{|c|c|c|c|c|c|}
\hline \multirow[b]{2}{*}{ Locus } & \multirow[b]{2}{*}{ Allele } & \multicolumn{4}{|c|}{ Population } \\
\hline & & Compensa & Cidade Nova & Downtown & Coroado \\
\hline $\operatorname{EST3}(\mathbf{n})$ & & 90 & 90 & 90 & 90 \\
\hline & 100 & 0.994 & 1.000 & 0.917 & 0.922 \\
\hline & 96 & 0.006 & 0.000 & 0.022 & 0.044 \\
\hline & 93 & 0.000 & 0.000 & 0.061 & 0.033 \\
\hline$\chi^{2} \mathrm{H}-\mathrm{W}$ & & $0.000(\mathrm{df}=1)^{\mathrm{ns}}$ & & $13.786(\mathrm{df}=3)^{*}$ & $0.591(\mathrm{df}=3)^{\mathrm{ns}}$ \\
\hline EST4 (n) & & 90 & 90 & 90 & 90 \\
\hline & 100 & 0.989 & 0.989 & 0.933 & 0,956 \\
\hline & 98 & 0.011 & 0.011 & 0.067 & 0.044 \\
\hline$\chi_{\text {H-W }}^{2}$ & & $0.006(\mathrm{df}=1)^{\mathrm{ns}}$ & $179.006(\mathrm{df}=1)^{*}$ & $97.672(\mathrm{df}=1)^{*}$ & $102.309(\mathrm{df}=1)^{*}$ \\
\hline $\operatorname{EST5}(\mathbf{n})$ & & 90 & 90 & 90 & 90 \\
\hline & 100 & 0.900 & 0.494 & 0.406 & 0.461 \\
\hline & 98 & 0.072 & 0.439 & 0.472 & 0.372 \\
\hline & 94 & 0.028 & 0.067 & 0.122 & 0.167 \\
\hline$\chi_{H-W}^{2}$ & & $33.649(\mathrm{df}=3)^{*}$ & $73.682(\mathrm{df}=3)^{*}$ & $22.067(\mathrm{df}=3)^{*}$ & $38.613(\mathrm{df}=3)^{*}$ \\
\hline$L A P 2(\mathbf{n})$ & & 90 & 90 & 90 & 90 \\
\hline & 100 & 0.567 & 0.550 & 0.628 & 0.450 \\
\hline & 98 & 0.433 & 0.450 & 0.372 & 0.550 \\
\hline$\chi_{\text {H-W }}^{2}$ & & $0.582(\mathrm{df}=1)^{\mathrm{ns}}$ & $17.780(\mathrm{df}=1)^{*}$ & $23.109(\mathrm{df}=1)^{*}$ & $8.637(\mathrm{df}=1)^{*}$ \\
\hline$L A P 5(\mathbf{n})$ & & 90 & 90 & 90 & 90 \\
\hline & 100 & 0.767 & 0.811 & 0.744 & 0.767 \\
\hline & 98 & 0.233 & 0.189 & 0.256 & 0.233 \\
\hline$\chi_{\mathrm{H}-\mathrm{W}}^{2}$ & & $1.680(\mathrm{df}=1)^{\mathrm{ns}}$ & $0.360(\mathrm{df}=1)^{\mathrm{ns}}$ & $0.189(\mathrm{df}=1)^{\mathrm{ns}}$ & $5.086(\mathrm{df}=1)^{* *}$ \\
\hline LAP6 (n) & & 90 & 90 & 90 & 90 \\
\hline & 100 & 0.989 & 1.000 & 0.989 & 1.000 \\
\hline & 98 & 0.011 & 0.000 & 0.011 & 0.000 \\
\hline$\chi_{\mathrm{H}-\mathrm{W}}^{2}$ & & $179.006(\mathrm{df}=1)^{*}$ & & $179.006(\mathrm{df}=1)^{*}$ & \\
\hline$P G I(\mathbf{n})$ & & 90 & 90 & 90 & 90 \\
\hline & 105 & 0.000 & 0.206 & 0.033 & 0.000 \\
\hline & 100 & 1.000 & 0.794 & 0.967 & 1.000 \\
\hline$\chi_{\text {H-W }}^{2}$ & & & $53.653(\mathrm{df}=1)^{*}$ & $10.603(\mathrm{df}=1)^{*}$ & \\
\hline
\end{tabular}


Table 1 (cont.)

\begin{tabular}{|c|c|c|c|c|c|}
\hline \multirow[b]{2}{*}{ Locus } & \multirow[b]{2}{*}{ Allele } & \multicolumn{4}{|c|}{ Population } \\
\hline & & Compensa & Cidade Nova & Downtown & Coroado \\
\hline \multirow[t]{3}{*}{$I D H(\mathbf{n})$} & & 90 & 90 & 90 & 90 \\
\hline & 110 & 0.311 & 0.183 & 0.200 & 0.128 \\
\hline & 100 & 0.689 & 0.817 & 0.800 & 0.872 \\
\hline$\chi_{\mathrm{H}-\mathrm{W}}^{2}$ & & $0.624(\mathrm{df}=1)^{\mathrm{ns}}$ & $1.913(\mathrm{df}=1)^{\mathrm{ns}}$ & $1.015(\mathrm{df}=1)^{\mathrm{ns}}$ & $6.158(\mathrm{df}=1)^{* *}$ \\
\hline \multirow[t]{3}{*}{$M D H(\mathbf{n})$} & & 90 & 90 & 90 & 90 \\
\hline & 110 & 0.350 & 0.217 & 0.300 & 0.422 \\
\hline & 100 & 0.650 & 0.783 & 0.700 & 0.578 \\
\hline$\chi_{\mathrm{H}-\mathrm{W}}^{2}$ & & $5.573(\mathrm{df}=1)^{* *}$ & $0.008(\mathrm{df}=1)^{\mathrm{ns}}$ & $0.000(\mathrm{df}=1)^{\mathrm{ns}}$ & $0.159(\mathrm{df}=1)^{\mathrm{ns}}$ \\
\hline \multirow[t]{3}{*}{$P G M(\mathbf{n})$} & & 90 & 90 & 90 & 90 \\
\hline & 105 & 0.050 & 0.139 & 0.183 & 0.167 \\
\hline & 100 & 0.767 & 0.694 & 0.606 & 0.650 \\
\hline$\chi_{\mathrm{H}-\mathrm{W}}^{2}$ & & $8.556(\mathrm{df}=3)^{* *}$ & $4.845(\mathrm{df}=3)^{\mathrm{ns}}$ & $16.160(\mathrm{df}=3)^{*}$ & $5.893(\mathrm{df}=3)^{\mathrm{ns}}$ \\
\hline
\end{tabular}

n - sample size.

$\chi^{2} \mathrm{H}-\mathrm{W}$ - chi-square/Hardy-Weinberg equilibrium.

df - degrees of freedom.

$* \mathrm{p}<0.01 ; * * \mathrm{p}<0.05 ;$ ns - not significant.

not significant, indicating equilibrium according to the Hardy-Weinberg equilibrium. Exceptions were found in the loci EST5, LAP6, MDH and PGM which presented significant deviations. In the Cidade Nova population, four out of the eight polymorphic loci were not in equilibrium (EST5, EST4, LAP2 and PGI). However, a higher number of polymorphic loci that showed significant deviations were found in the Downtown (EST3, EST4, EST5, LAP2, LAP6, PGI and PGM), and in the Coroado (EST5, EST4, $L A P 2$, LAP5 and $I D H$ ) populations as well. According to the four populations genotype frequency analyses, only $45 \%$ of the polymorphic loci were in Hardy-Weinberg equilibrium.

The genetic variability estimates in the four populations are shown in Table 2. The Downtown population was the most polymorphic $(\mathrm{P}=55.6 \%)$, with the largest number of alleles per locus (1.7) and highest level of heterozygosity $\left(\mathrm{H}_{\mathrm{o}}=0.152\right)$. The least variability was found in the Coroado and Cidade Nova $(\mathrm{P}=44.4 \%)$ populations with the smallest number of alleles per locus (1.6), and the latter presented the least observed heterozygosity $\left(\mathrm{H}_{\mathrm{o}}=0.109\right)$.

Genetic structure of the populations analysed through Wright's $F$ statistics showed higher $F_{\text {is }}$ mean value relative to $\mathrm{F}_{\mathrm{st}}(0.164>0.048)$. Higher $\mathrm{F}_{\text {is }}$ values as compared with $\mathrm{F}_{\text {st }}$ were found in loci LAP6, EST4 and PGI with 1.000, 0.912 and 0.687 respectively, suggesting a certain intrapopulational differentiation (Table 3 ). Population structure was also tested at different hierarchical levels using $\mathrm{F}_{\mathrm{st}}$ by AMOVA analysis (Table 4). Most of the variation was found within populations (95\%), indicating large differentiation within population differentiation. There was little variation among populations $(5 \%)$.

However, the genetic distance values shown in Table $5(\mathrm{D}=0.003-0.016)$ indicate that these populations are very similar genetically, grouping the Cidade Nova, Downtown and Coroado populations in one single "cluster", while the Compensa population was separated in another "cluster" (Figure 1).

Table 2 - Estimate of measures of genetic variability in A. aegypti populations.

\begin{tabular}{|c|c|c|c|c|c|}
\hline \multirow[t]{2}{*}{ Population } & \multirow[t]{2}{*}{ Mean sample size/locus } & \multirow[t]{2}{*}{ Mean $n^{\circ}$ of alleles/locus } & \multirow[t]{2}{*}{ \% Polymorphic loci* } & \multicolumn{2}{|c|}{ Mean heterozygosity } \\
\hline & & & & Observed & Expected $* *$ \\
\hline Compensa & $90.0 \pm 0.0$ & $1.6 \pm 0.2$ & 50.0 & $0.117 \pm 0.043$ & $0.131 \pm 0.046$ \\
\hline Cidade Nova & $90.0 \pm 0.0$ & $1.6 \pm 0.2$ & 44.4 & $0.109 \pm 0.037$ & $0.157 \pm 0.050$ \\
\hline Downtown & $90.0 \pm 0.0$ & $1.7 \pm 0.2$ & 55.6 & $0.152 \pm 0.052$ & $0.174 \pm 0.052$ \\
\hline Coroado & $90.0 \pm 0.0$ & $1.6 \pm 0.2$ & 44.4 & $0.143 \pm 0.049$ & $0.164 \pm 0.053$ \\
\hline
\end{tabular}

* A locus was considered polymorphic if more than one allele was detected.

** Expected heterozygosity of Hardy-Weinberg, Nei's unbiased estimate (Nei, 1978). 
Table 3 - Genetic structure analysis of Aedes aegypti populations from Manaus, using Wright's F statistics.

\begin{tabular}{lccl}
\hline Locus & $\mathrm{F}_{\text {is }}$ & $\mathrm{F}_{\text {it }}$ & \multicolumn{1}{c}{$\mathrm{F}_{\text {st }}$} \\
\hline EST3 & 0.006 & 0.036 & $0.035^{* * *}$ \\
EST4 & 0.912 & 0.914 & 0.017 \\
EST5 & 0.473 & 0.536 & $0.147^{* * *}$ \\
LAP2 & 0.287 & 0.299 & $0.016^{*}$ \\
LAP5 & -0.030 & -0.026 & -0.001 \\
LAP6 & 1.000 & 1.000 & 0.001 \\
PGI & 0.687 & 0.728 & $0.160^{* * *}$ \\
IDH & -0.049 & -0.021 & $0.030^{* * *}$ \\
MDH1 & 0.047 & 0.072 & $0.028^{* * *}$ \\
PGM & -0.089 & -0.075 & $0.012^{* * *}$ \\
\hline Mean & 0.164 & 0.198 & $0.048^{* * *}$ \\
\hline
\end{tabular}

$\mathrm{F}_{\text {is }}=$ coefficient of inbreeding among individuals in the subpopulations; $\mathrm{F}_{\mathrm{it}}=$ degree of genetic differentiation among the total populations; $\mathrm{F}_{\mathrm{st}}=$ degree of genetic differentiation among the subpopulations; levels of significance for $\mathrm{F}_{\mathrm{st}}>0$ are: ${ }^{*} \mathrm{p}<0.005 ;{ }^{* *} \mathrm{p}<0.01 ;{ }^{* *} \mathrm{p}>0.001$.

Table 4 - Hierarchical analysis of molecular variance of four Aedes aegypti populations from Manaus.

\begin{tabular}{lrcc}
\hline Source of variation & d.f & $\begin{array}{c}\text { \% Variation } \\
F_{s t}\end{array}$ & $\begin{array}{c}\text { P } \\
\text { st }\end{array}$ \\
\hline Among populations & 3 & 4.88 & $<0.001$ \\
Within populations & 716 & 95.12 & $<0.001$ \\
\hline
\end{tabular}

$\%$, percentage molecular variation explained by the hierarchical level; $\mathrm{P}$, level of significance for the distribution for that hierarchical level being different from random.

Table 5 - Matrix of genetic distance and similarity among the four Aedes aegypti populations.

\begin{tabular}{lcccc}
\hline Population & Compensa & Cidade Nova & Downtown & Coroado \\
\hline Compensa & $* * * * *$ & 0.986 & 0.984 & 0.987 \\
Cidade Nova & 0.014 & $* * * * *$ & 0.997 & 0.993 \\
Downtown & 0.016 & 0.003 & $* * * * *$ & 0.997 \\
Coroado & 0.013 & 0.007 & 0.003 & $* * * * *$ \\
\hline
\end{tabular}

The values below the diagonal correspond to unbiased genetic distance and those above the diagonal correspond to unbiased genetic identity (Nei, 1978).

\section{Discussion}

The analysis of the polymorphism found in the four populations, through the allelic frequencies, showed that most loci in Hardy-Weinberg equilibrium were in the Compensa population. In the four population group, it was verified that only $45 \%$ of loci were in equilibrium. Similar results were found in the Guariba population (SP) for this vector by Dinardo-Miranda and Contel (1996). Con-

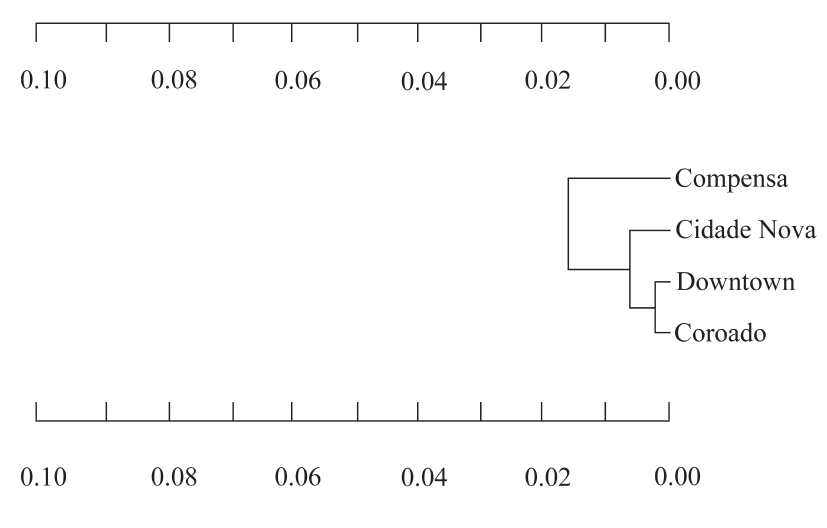

Figure 1 - Dendrogram resulting from grouping populations of Aedes aegypti on the basis genetic distance by the unweighted pairing group method which arithmetic mean - UPGMA (Nei, 1978).

sidering the three populations from their study, it was found that only (35\%) of the loci were in equilibrium. However, divergent findings from other countries' A. aegypti populations have been reported, such as observed by Tabachnick and Powell (1978), where most analysed loci did not show significant deviations for the Hardy-Weinberg equilibrium. Likewise, Harrington et al. (1984) found similar results when analysing 20 populations of this vector.

Significant deviations from the expected values of the Hardy-Weinberg equilibrium were found in some loci. These deviations are due to the occurrence of a single homozygote individual for one rare allele, such as the alleles $L A P 6^{* 98}$ in the Compensa, EST4*98 in the Cidade Nova, $L A P 6^{*} 98$ and $P G I^{* 105}$ in the Downtown populations. Similar findings were reported by Scarpassa et al. (1999) in Anopheles nuneztovari populations from Tucuruí (PA) for three nonspecific esterase loci.

One of the most important implications of Hardy-Weinberg equilibrium is that when an allele is rare, most of the individuals should be heterozygous (Hartl, 1981). For the loci with deviation from genetic equilibrium due to the heterozygotes deficiency, Crouau-Roy (1988) mentioned that usually these deficiencies are found in some enzymatic loci and/or in some populations presenting other loci whose genotype proportions are in equilibrium.

The Downtown population presented the highest polymorphism indexes. These findings are similar to those detected in populations of São Paulo State by Dinardo-Miranda and Contel (1996), who found a polymorphic loci rate ranging from $37.5 \%$ in the Guariba to $50 \%$ in the Ribeirão Preto populations. In populations of this species collected in Kenya, Tabachnick and Powell (1976) found variation in 59\% of the loci. Harrington et al. (1984), found a polymorphic loci rate ranging from $30 \%$ to $40 \%$ in A. aegypti populations from Houston. Recently, de Sousa et al. (2000) detected polymorphic loci rates ranging from $27.3 \%$ to $63.6 \%$ in Argentinean populations.

Higher mean heterozygosity values detected in the Downtown population indicated that this population was 
the most variable among the four studied. These values resemble those found by de Sousa et al. (2000) who detected expected mean heterozygosities ranging from 0.090 to 0.161 for 11 allozymic loci in A. aegypti samples from Argentina. This also resembles the analyses reported by Tabachnick et al. (1979), where the expected mean heterozygosity was of 0.141 for domestic, and of 0.163 for East African wild populations. Lower expected mean heterozygosity values for this species $\left(\mathrm{H}_{\mathrm{e}}=0.118 \pm 0.009\right)$ were detected by Tabachnick (1982) in the Caribbean, and by Harrington et al. (1984) $\left(\mathrm{H}_{\mathrm{e}}=0.097 \pm 0.055\right)$ in Houston populations. Nevertheless, Dinardo-Miranda and Contel (1996) obtained expected mean heterozygosity value divergent findings, ranging from 0.48 to 0.53 , in this mosquito's São Paulo populations.

Higher heterozygosity estimates have been detected in this species with the use of other molecular markers. Apostol et al. (1996) detected mean heterozygosity values equal to 0.354 , twice the level found with the use of isozymes in Puerto Rico populations, using RAPD-PCR. Yan et al. (1999) found mean heterozygosity values of 0.39 in this vector's populations with the use of AFLP, and this value was similar in all populations, whereas the values were from 0.44 to 0.58 with the use of RFLP. Similar estimates $\left(\mathrm{H}_{\mathrm{e}}=0.350\right)$ by using RAPD-PCR in this species were reported by de Sousa et al. (2001).

On the basis of the data presented, it may be inferred that the heterozygosity values found in this study by using isoenzymes would have a very close correspondence to those found with other markers, and that the A. aegypti populations here analysed would not be less polymorphic than the others analysed around the world. Therefore, heterozygosity indexes found in the Manaus $A$. aegypti populations, point out that there is no "founder effect" occurrence. Since according to Nei et al. (1975), for a new population started by 2 to 10 founder individuals, heterozygosity undergoes an initial decrease whose recovery will come about slowly, and only following nearly $10^{5}$ generations will be established back to the initial population levels.

Therefore, these data suggest that the in loci with distribution of their genotypic frequencies according to the expected by the Hardy-Weinberg equilibrium, the couplings are random between the individuals. However, for those where significant deviations between found and expected frequencies were detected, it is possible that it is a result of a higher number of found than expected homozygotes, detected in the majority of loci in non-equilibrium in this study's populations. This hypothesis is forwarded by Failloux et al. (1995) in studies on populations of this vector, as well as by Santos et al. (1999) on Anopheles darlingi populations from the Amazonian region.

Genetic structure data from Wright's F statistics showed disequilibrium resulting from homozygote excess and suggested a certain intrapopulational differentiation, in which $F_{\text {is }}$ values were higher than $F_{\text {st }}$ values. Similar results in French Polynesian A. aegypti populations were reported by Failloux et al. (1995), who detected heterozygote deficiency in loci EST1, EST3 and PGM $\left(\mathrm{F}_{\mathrm{is}}=0.26 ; 0.20\right.$ and 0.13 , respectively). de Sousa et al. (2000) found $\mathrm{F}_{\mathrm{st}}$ mean value equal to 0.065 , in this vector's Argentinean populations indicating low levels of genetic differentiation among populations from different localities. Nevertheless, Dinardo-Miranda and Contel (1996) found lower $\mathrm{F}_{\mathrm{st}}$ values (0.018) in São Paulo populations. In their study the author considers that even though actual $\mathrm{F}_{\text {st }}$ values had been low they nevertheless were significant, and indicate a differentiation between populations, making it possible to assert that the allelic frequency variability origin is intrapopulacional $\left(\mathrm{F}_{\text {is }}=0.057\right)$.

According to Eanes and Koehn (1978) population genetic structures is a consequence from the coupling patterns, and the genetic flow magnitude between populations and this is expressed by the Hardy-Weinberg equilibrium deviation and by the amount of differentiation or allelic frequency between the populations. They further consider that the high genetic flow rates among sub-populations and the tendency for intrapopulational random coupling may lead to a genetic structure decrease. Given this information, it is possible to admit that the $\mathrm{F}_{\mathrm{st}}$ values detected in this study may indicate the onset of a genetic flow reduction process as well as of the non random couplings occurrence, since the $F_{\text {is }}$ value was relatively high. Tabachnick and Wallis (1985) and Failloux et al. (1995), reported similar findings on this mosquito populations genetic structure to those obtained in Manaus, where control measures of both immature and winged forms with insecticide systematic applications led to a decrease in population size within a determined period of time. However, a population increase occurs again whenever there is a relaxation of these measures.

The genetic distance values found among the four Manaus populations were small, indicating that these populations are very similar. These findings are similar to those detected in São Paulo populations by Dinardo-Miranda and Contel (1996) who found genetic distance values between 0.009 and 0.018. Tabachnick et al. (1979) and Wallis et al. (1984) working with this vector's populations who found genetic distance values from 0.002 to 0.082 and 0.002 to 0.084 . These findings confirm a low genetic differentiation level among all the populations around the world, including those in Brazil. Taking the direct relation between genetic distance and evolving time into account (Nei, 1972) it may be inferred that, for $A$. aegypti, the divergence between populations is fairly recent.

The dendrogram in Figure 1 showed that the Cidade Nova, Downtown and Coroado populations were grouped in a "cluster", being closely related, whereas the Compensa population was separated into another "cluster". The present study showed to be very useful since it helped to understand the polymorphism levels and indexes which 
determine the genetic structure of the A. aegypti populations that infest the city of Manaus, and thus, subsidise these vectors' control strategies. Currently, vector control is the only available method for reducing the incidence of dengue fever. Mosquito populations can be limited by insecticides used against larvae and/or adults. Extended use of insecticides for dengue control may enhance the resistance to insecticides in mosquito populations (Pasteur and Raymond, 1996). Furthermore, rebuilding from selected resistant individuals gives rise to a population genetically different from the original one. Therefore, knowledge about geographical genetic variation in $A$. aegypti populations regarding dengue transmission would be informative. However, further molecular studies involving other Brazilian populations must be carried out in the attempt to provide more information on the genetic structure of this vector's populations, its variability and possibly about its vectorial ability, insecticide resistance and ecological adaptation.

\section{Acknowledgments}

We would like to thank Mr. Jorge Antunes for helping to correct the English version of the manuscript. CAPES/PICDT and CNPq, PPI/INPA 3260 e 3110 supported this research.

\section{References}

Apostol BL, Black $4^{\text {th }}$ WC, Reiter P and Miller BR (1996) Population genetics with RAPD-PCR markers: the breeding structure of Aedes aegypti in Puerto Rico. Heredity 76:325-334.

Chow VTK, Chan YC, Yong R, Lee KM, Lim LK, Chung YK, Lam-Phua SG and Tan BT (1998) Monitoring of dengue viruses in field-caught Aedes aegypti and Aedes albopictus mosquitoes by a type-specific polymerase chain reaction and cycle sequencing. Am J Trop Med Hyg 58:578-586.

Consoli RAGB and Lourenço-de-Oliveira R (1994). Principais Mosquitos de Importância Sanitária no Brasil. FIOCRUZ, Rio de Janeiro, 225 p.

Crouau-Roy B (1998) Genetic structure of cave-dwelling beetles populations: significant deficienci of heterozygotes. Heredity 60:321-327.

de Sousa GB, Aviles G and Gardenal CN (2000) Allozymic polymorphism in Aedes aegypti populations from Argentina. J Am Mosq Control Assoc 16:206-209.

de Sousa GB, Blanco A and Gardenal CN (2001) Genetic relationships among Aedes aegypti (Diptera: Culicidae) populations from Argentina using random amplified polymorphic DNA polymerase chain reaction markers. J Med Entomol 38:371-375.

Dinardo-Miranda, LL and Contel EPB (1996) Variability in natural populations of Aedes aegypti (Diptera, Culicidae) from Brazil. J Med Entomol 33:726-733.

Eanes WF and Koehn RK (1978) An analysis of genetic structure in the monarch butterfly, Danaus plexippus L. Evolution 32:784-797.
Failloux AB, Darius H and Pasteur N (1995) Genetic differentiation of Aedes aegypti the vector of dengue French Polynesia. J Am Mosq Control Assoc 11:457-462.

Harrington MA, Haecker CS, Cheng ML and Ferrel RE (1984) Genetic variation in urban population of Aedes aegypti (Diptera, Culicidae). J Med Entomol 21:706-710.

Hartl DL (1981) A Primer of Population Genetics. Sunderland, Massachusetts, Sinauer Associates, Inc. Publishers.

Honório AN and Lourenço-de-Oliveira R (2001) Freqüência de larvas e pupas de Aedes aegypti e Aedes albopictus em armadilhas, Brasil. Rev Saúde Pública 35:385-391.

Michalakis Y and Excoffier L (1996) A generic estimation of population subdivision using distances between alleles with special reference for microsatellite loci. Genetics 142:1061-1064.

Nei M, Maruyama T and Chakraborty R (1975) The bottleneck effect and genetic variability in populations. Evolution 29:110 .

Nei M (1972) Genetic distance between populations. Am Nat 106:283-292.

Nei M (1978). Estimation of average heterozygosity and genetic distance from a small number of individuals. Genetics 89:583-590.

Pasteur N and Raymond M (1996) Insecticide resistance genes in mosquitoes their mutations, migration, and selection in field populations. J Hered 87:444-449.

Ravel S, Hervé JP, Diarrassouba S, Kone A and Cuny G (2002) Microsatellite markers for population genetic studies in Aedes aegypti (Diptera: Culicidae) from Côte d' Ivoire: evidence for a microgeographic genetic differentiation of mosquitoes from Bouaké. Acta Trop 82:39-49.

Santos JMM, Contel EPB and Keer WE (1981) Biologia de anofelinos amazônicos I - Ciclo biológico, postura e estádios de Anopheles darlingi Root, 1926 (Diptera: Culicidae) da Rodovia Manaus/Boa Vista. Acta Amazonica 11:789-797.

Santos JMM, Tadei WP and Contel EPB (1996) Electrophoretic analysis of 11 enzymes in natural populations of Anopheles (N.) darlingi Root, 1926 (Diptera: Culicidae) in the Amazon region. Acta Amazonica 26:97-114.

Santos JMM, Lobo JA, Tadei WP and Contel EPB (1999) Intrapopulational genetic differentiation in Anopheles (N.) darlingi Root, 1926 (Diptera: Culicidae) in the Amazon Region. Genet Mol Biol 22:325-331.

Scarpassa VM, Tadei WP and Suarez MF (1999) Population structure and genetic divergence in Anopheles nuneztovari (Diptera: Culicidae) from Brazil and Colombia. Am J Trop Med Hyg 60:1010-1018.

Schatzmayr HG (2000) Dengue situation in Brazil by year 2000 Mem Inst Oswaldo Cruz 95 (Suppl. 1):179-181.

Schneider S, Roessli D and Excoffier L (2000) Arlequin ver. 2000: A Software for population genetic data analysis. Genetics and Biometry Laboratory, University of Geneva, Switzerland.

Steiner WWM and Joslyn DJ (1979). Electrophoretic techniques for the genetic study of mosquitoes. Mosq News 39:35-54.

Swofford DL and Selander RB (1981) Biosys - 1: A fortran program for the comprehensive analyses of electrophoretic data in population genetics and systematics. J Hered 72:281-283.

Tabachnick WJ and Powell JR (1976) Allozymic variation in the yellow fever mosquito, Aedes aegypti. Genetics 83:74-76. 
Tabachnick WJ and Powell JR (1978) Genetic structure of the East African domestic populations of Aedes aegypti. Nature 272:535-537.

Tabachnick WJ, Munstermann LE and Powell JR (1979) Genetic distinctness of sympatric forms of Aedes aegypti in East Africa. Evolution 33:287-295.

Tabachnick WJ (1982) Geographic and temporal patterns of genetic variation of Aedes aegypti in New Orleans. Am J Trop Hyg 31:849-853.

Tabachnick WJ and Wallis GP (1985) Population genetic structure of the yellow fever mosquito Aedes aegypti in the Carib- bean: ecological considerations. International Mosquito Ecology Workshop Symposium. Vero Beach, Florida.

Wallis GP, Tabachnick WJ and Powell JR (1984) Genetic heterogeneity among Caribbean populations of Aedes aegypti. Am J Trop Med Hyg 33:492-498.

Weir BS and Cockerham CC (1984) Estimating F-Statistics for the analysis of population structure. Evolution 38:15381370.

Yan G, Romero-Severson J, Walton M, Chadee DD and Severson DW (1999) Population genetics of the yellow fever mosquito in Trinidad: Comparisons of amplified fragment length polymorphism (AFLP) and restriction fragment length polymorphism (RFLP) markers. Mol Ecol 8:951-963. 